\title{
Correction to: Antiobesity potential of Piperonal: promising modulation of body composition, lipid profiles and obesogenic marker expression in HFD-induced obese rats
}

Balaji Meriga ${ }^{1 *}$, Brahmanaidu Parim ${ }^{1,2}$, Venkata Rao Chunduri ${ }^{3}$, Ramavat Ravindar Naik ${ }^{4}$, Harishankar Nemani ${ }^{4}$, Pothani Suresh ${ }^{4}$, Saravanan Ganapathy ${ }^{5}$ and V. V. Sathibabu Uddandrao ${ }^{5}$

\section{Correction}

Following publication of the original article [1], the authors requested a correction to the name of one of the co-authors. The correct name and spelling is V.V. Sathibabu Uddandrao.

The original article has been updated.

\begin{abstract}
Author details
${ }^{1}$ Animal Physiology and Biochemistry Laboratory, Department of Biochemistry, Sri Venkateswara University, Tirupati, Andhra Pradesh 517502, India. ${ }^{2}$ Present Address: Department of Bio-Technology, VSU College of Sciences, Vikrama Simhapuri University, Nellore, Andhra Pradesh 524320, India. ${ }^{3}$ Department of Chemistry, Sri Venkateswara University, Tirupati, Andhra Pradesh 517502, India. ${ }^{4}$ National Center for Laboratory Animal Sciences, National Institute of Nutrition (Indian Council of Medical Research), Hyderabad, India. ${ }^{5}$ Department of Biochemistry, Center for Biological Sciences, K. S. Rangasamy College of Arts Science, Tiruchengode, Tamil Nadu, India.
\end{abstract}

Received: 30 November 2017 Accepted: 30 November 2017

Published online: 06 December 2017

\section{Reference}

1. Meriga B, Parim B, Chunduri VR, Naik RR, Nemani H, Suresh P, Ganapathy S, WU SB. Antiobesity potential of Piperonal: promising modulation of body composition, lipid profiles and obesogenic marker expression in HFDinduced obese rats. Nutr Metab. 2017;14:72. https://doi.org/10.1186/s12986017-0228-9.

\footnotetext{
* Correspondence: balaji.meriga@gmail.com

${ }^{1}$ Animal Physiology and Biochemistry Laboratory, Department of

Biochemistry, Sri Venkateswara University, Tirupati, Andhra Pradesh 517502,

India
} 